\title{
Rapid assay of picogram level of sudan I in hot chilli sauce by flow injection chemiluminescence
}

\author{
Xiaofei Gao, Houyong Liu, Zhenghua Song *, Xili He and Faxin Dong \\ Department of Chemistry, Northwest University, 710069, Xi'an, China
}

\begin{abstract}
A novel chemiluminescence method for the assay of sudan I was designed using flow injection with chemiluminescence detection. The proposed method was based on the increment effect of sudan I on the chemiluminescence intensity in the luminol- $-\mathrm{KIO}_{4}$ system. The increment of chemiluminescence intensity was correlated with the sudan I concentration in the range from 0.1 to $10 \mathrm{pg} \mathrm{ml}^{-1}$, and the determination could be performed in $0.5 \mathrm{~min}$ in flow rate of $2 \mathrm{ml} \mathrm{min}^{-1}$, including sampling and washing, giving a throughput of $120 \mathrm{~h}^{-1}$ with a relative standard deviation of less than $5.0 \%$. The method had been successfully applied to the assay of sudan I in Pixian douban, Golden mark guilin chilli sauce and Golden mark satay sauce, and the recovery was $90.0-103.8 \%$.
\end{abstract}

Keywords: Sudan I, chemiluminescence, luminol, flow injection

\section{Introduction}

Sudan I (see Scheme 1) is widely used to color other materials, such as hydrocarbon solvents, oils, fats, waxes, and shoe and floor polishes [1]. In vivo studies on the metabolism of sudan I in rabbits revealed that this compound is metabolized primarily in the liver by oxidative or reductive reactions [2,3]. It is considered to be a genotoxic carinogen [4] and its presence is not permitted in foodstuffs for any purpose at any level. Sudan dyes may cause cancer to people and hence sudan dyes at any level is not safe for the human. However, sudan dyes have been found as a contaminant in chilli powder [5]. Soups, sauces and ready meals that use contaminated chilli powder are the main sources for sudan dyes. It has been banned as a food colourant throughout the Europe since 2003, due to its carcinogenic properties. However despite this, it has been used by some companies to manufacture chilli powder.

As reported in the literature, dealing with the analytical chemistry of sudan I, the usually proposed methods for the determination of the compound were based on liquid chromatography (LC) with mass spectrometry (MS) [5-7], UV/Vis [7-10], photodiode-array detection [11]. Other methods for determination of sudan I included molecularly imprinted solid phase extraction with UV detection [12], the mass spectrometric method [13], solid-phase spectrophotometric method [14,15].

Since it was first reported by Albrecht in 1928 [16], the chemiluminescence (CL) resulting from the reaction of luminol and oxidants has been extensively studied and applied to the determination of a range of inorganic and organic species. For example, Palilis and Powe $[17,18]$ described analytical applications

\footnotetext{
*Corresponding author. Fax: +86 29 88303798; E-mail: songzhenghua@ hotmail.com.
} 


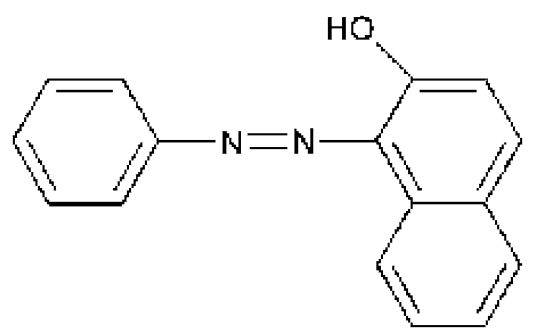

Scheme 1. Structure of sudan I.

of CL reactions. Compared with other methods for the assay of sudan I, CL method offers the advantages of simplicity of apparatus, low reagent consumption, higher sensitivity and higher sample throughput. We have currently reported on the luminol- $\mathrm{H}_{2} \mathrm{O}_{2}$ system to determine of sudan I, giving a calibration graph linear over the concentration from $10 \mathrm{pg} \mathrm{ml}^{-1}$ to $7 \mathrm{ng} \mathrm{ml}^{-1}$ with the detection limit of $3 \mathrm{pg} \mathrm{ml}^{-1}$ [19]. In this work, the proposed procedure is the most sensitive method reported so far. It was observed that sudan I could sharply intensify the CL derived from the luminol- $\mathrm{KIO}_{4}$ system, and the CL intensity responded to the concentration of sudan I linearly ranging from $1 \times 10^{-13} \mathrm{~g} \mathrm{ml}^{-1}$ to $1 \times 10^{-11} \mathrm{~g} \mathrm{ml}^{-1}$ with the detection limit of $0.03 \mathrm{pg} \mathrm{ml}^{-1}$. The determination could be performed in $0.5 \mathrm{~min}$ in flow rate of $2 \mathrm{ml} \mathrm{min}{ }^{-1}$, including sampling and washing, giving a throughput of $120 \mathrm{~h}^{-1}$ with a relative standard deviation of less than $5.0 \%$. The method has been successfully applied to the assay of sudan I, and the recovery was $90.0-103.8 \%$.

\section{Experimental section}

\subsection{Reagents}

All chemicals used were of analytical reagent grade. Water purified in a Milli-Q system (Millipore, Bedford, MA, USA) was used throughout. Luminol (Fluka, biochemika) were obtained from Xi'an Medicine Purchasing and Supply Station, China. Potassium periodate was purchased from Xi' an Chemical Reagent Plant. Standard solution and samples of sudan I were supplied by Shaanxi Entry-Exit Inspection and Quarantine Bureau.

A standard solution of sudan I $\left(1 \mu \mathrm{g} \mathrm{ml}^{-1}\right)$ was stored at $4^{\circ} \mathrm{C}$. Working strength solutions were prepared daily from the above stock solution as required. Luminol $\left(2.5 \times 10^{-2} \mathrm{~mol}^{-1}\right)$ was prepared by dissolving $4.4 \mathrm{~g}$ luminol in 11 of $0.1 \mathrm{~mol}^{-1} \mathrm{NaOH}$ solution. A $0.04 \mathrm{~mol}^{-1}$ stock standard solution of periodate was prepared by dissolving the solid in distilled water.

\subsection{Apparatus}

A schematic diagram of the CL flow injection analysis system was shown in Fig. 1. A peristaltic pump was utilized to deliver all flow streams. PTFE tubing $(1.0 \mathrm{~mm}$ i.d.) was used as connection material in the flow system. A six-way valve with a loop of $100 \mu$ was employed for sampling. The flow cell was made by coiling $30 \mathrm{~cm}$ of colorless glass tube (i.d. $2 \mathrm{~mm}$ ) into a spiral disk shape with a diameter of $2 \mathrm{~cm}$ and placed close to the photomultiplier tube (PMT) (Hamamatsu, Model IP28). The CL signal produced in the flow cell was detected without wavelength discrimination, and the PMT output was amplified and quantified by a luminosity meter (Xi'an Remax Electronic Science-Tech. Co. Ltd. Model GD-1) connected to a recorder (Shanghai Dahua Instrument and Meter Plant, Model XWT-206). 


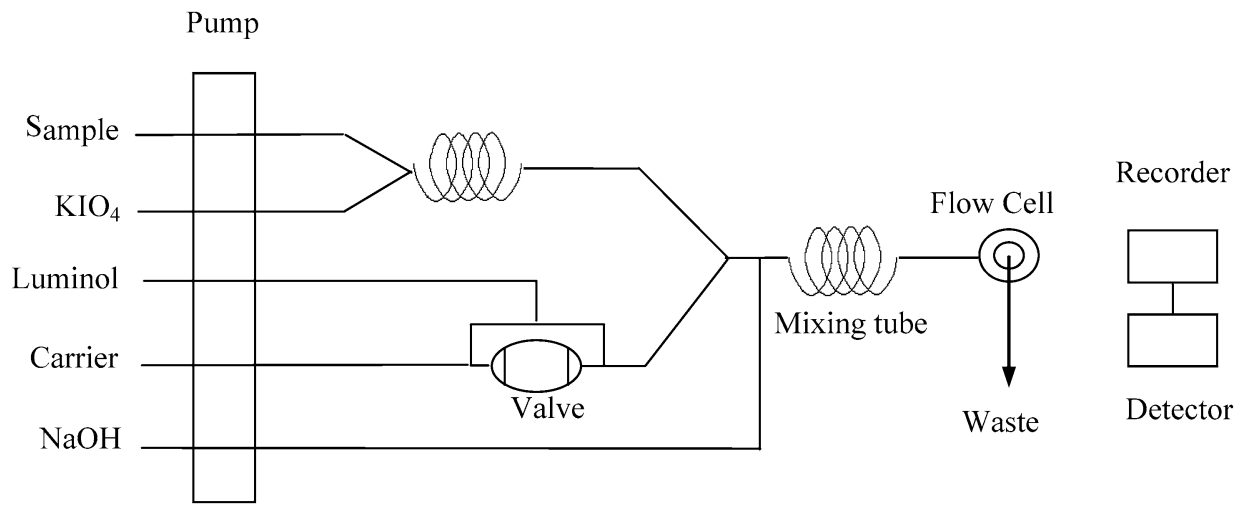

Figure 1. Schematic diagram of the present FI-CL system for sudan I.

\subsection{Procedures}

As shown in Fig. 1, flow lines were inserted into the sample, $\mathrm{KIO}_{4}$, luminol, carrier (pure water), and sodium hydroxide solutions, respectively. The pump was started at a constant speed of $2.0 \mathrm{ml} \mathrm{min}-1$ to wash the whole system until a stable baseline was recorded. Then $100 \mu \mathrm{l}$ luminol solution was injected into the carrier stream by injection valve, merged with the mixed solution stream of sudan $\mathrm{I}$ and $\mathrm{KIO}_{4}$. The mixed solution in an alkaline medium was delivered into the CL cell, producing CL emission, detected by the PMT and luminometer. The concentration of the sample was quantified by the increment of CL intensity, $\Delta I=I_{\mathrm{s}}-I_{\mathrm{o}}$, where $I_{\mathrm{s}}$ and $I_{\mathrm{o}}$ were CL signals in the presence and in the absence of sudan I, respectively.

\subsection{Sample preparation}

The proposed procedure for the determination of sudan I was applied to hot chilli sauce. Contaminated hot chilli sauces were grounded to a fine powder using a Multifunctional Food Cooking Units (Shangdong Jiu Yang Small Electrical Appliance Co. Ltd., Model JYL-350), about $3 \mathrm{~g}$ was weighted and dissolved ultrasonically for $30 \mathrm{~min}$ in 1:1 (v/v) acetonitrile and water in PTFE digestion can, incubating, centrifugating for $10 \mathrm{~min}$, and then the upper clear solution was determined.

\section{Results and discussions}

\subsection{CL intensity-time profile}

The CL intensity-time profile of luminol- $\mathrm{KIO}_{4}$ was examined by the flow injection method. It could be seen in Fig. 2 that the CL signal of luminol- $-\mathrm{KIO}_{4}$ reached a maximum in $11 \mathrm{~s}$ after injection, and then died within $30 \mathrm{~s}$. On joining of the sample into the above mixing solution, an enhanced CL signal was recorded. The peak heights of the CL emission were proportional to the sudan I concentration.

\subsection{Effect of luminol, periodate and sodium hydroxide concentration}

The maximum CL signal was found with luminol at $7 \times 10^{-6} \mathrm{~mol} \mathrm{l}^{-1}$, with periodate at $5 \times$ $10^{-5} \mathrm{~mol} \mathrm{l}^{-1}$, and $0.025 \mathrm{~mol} \mathrm{l}^{-1}$ for sodium hydroxide, which were selected as optional condition. 


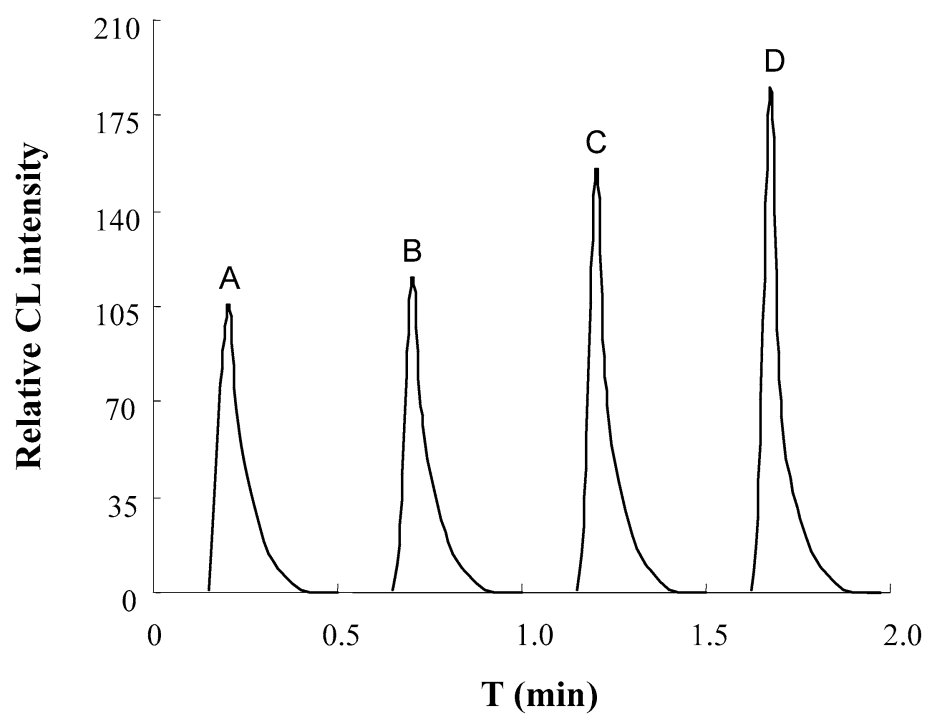

Figure 2. The CL intensity-time profile. A: CL intensity in the absence of sudan I; B: CL intensity in the presence of $0.1 \mathrm{pg} \mathrm{ml}^{-1}$ sudan I; C: CL intensity in the presence of $1.0 \mathrm{pg} \mathrm{ml}^{-1}$ sudan I; D: CL intensity in the presence of $10 \mathrm{pg} \mathrm{ml}^{-1}$ sudan I.

\subsection{Effect of flow rate and the length of mixing tubing}

The flow rate of $2.0 \mathrm{ml} \mathrm{min}^{-1}$ was selected as an appropriate condition considering both good analytical precision and lower solution consumption, and it was found that an $11.0 \mathrm{~cm}$ mixing tube afforded the best results with good sensitivity and reproducibility.

\subsection{Performance of proposed method for sudan I measurement}

A series of sudan I standard solutions were injected into the manifold depicted in Fig. 1 under the above optimum conditions to test the linearity of sudan I. The enhancement of CL intensity was found to be proportional with the sudan I concentration. The linear range was from 0.1 to $10 \mathrm{pg} \mathrm{m}^{-1}$ and the regression equation was $\Delta I_{\mathrm{CL}}=7.0243 C_{\text {sudan I }}+109.9\left(R^{2}=0.9987, n=5\right)$. The relative standard deviations of five determinations were $4.48,3.52,2.12 \%$ with sudan I concentrations of 0.1 , $1.0,10 \mathrm{pg} \mathrm{ml}^{-1}$. At a flow rate of $2.0 \mathrm{ml} \mathrm{min}^{-1}$, the determination of analyte could be performed in 0.5 min, including sampling and washing, giving a throughput of about 120 times per hour with a relative standard deviation of less than $5.0 \%$.

\subsection{Interference studies}

The effect of interferents was tested by analyzing a standard solution of sudan I $\left(10 \mathrm{pg} \mathrm{ml}^{-1}\right)$ to which increasing amounts of interferents were added. The tolerable limit of interferents was taken if it caused a relative error of less than $5 \%$. The tolerable concentrations were over $50 \mu \mathrm{g} \mathrm{ml}^{-1}$ for $\mathrm{K}^{+}, \mathrm{Cl}^{-}, \mathrm{I}^{-}, \mathrm{NO}_{3}^{-}$, $\mathrm{Ac}^{-}, \mathrm{HCO}_{3}^{-}, \mathrm{PO}_{4}^{3-}, \mathrm{Cr}_{2} \mathrm{O}_{7}^{2-}, \mathrm{SO}_{3}^{2-}, \mathrm{Br}^{-}$, malic acid, citrate, oxalate, and tartrate, $20 \mu \mathrm{g} \mathrm{ml}^{-1}$ for $\mathrm{NH}_{4}^{+}$, $\mathrm{Mg}^{2+}, \mathrm{Ba}^{2+}, \mathrm{Zn}^{2+}, \mathrm{Mn}^{2+}$ and $\mathrm{Ca}^{2+}, 15 \mu \mathrm{ml}^{-1}$ for methanol, ethanol, sucrose, urea, gelatin, globulin, starch, and dextrin. $10 \mu \mathrm{g} \mathrm{ml}^{-1}$ for $\mathrm{Ni}^{2+}, 5 \mu \mathrm{g} \mathrm{ml}^{-1}$ for glucose and polyvinyl alcohol, $3 \mu \mathrm{g} \mathrm{ml}^{-1}$ for $\mathrm{Cr}^{3+}, 0.5 \mu \mathrm{g} \mathrm{ml}^{-1}$ for $\mathrm{Fe}^{3+}$ and $\mathrm{Fe}^{2+}, 0.1 \mu \mathrm{g} \mathrm{ml}^{-1}$ for baicalin, $50 \mathrm{ng} \mathrm{ml}^{-1}$ for uric acid, $30 \mathrm{ng} \mathrm{ml}^{-1}$ for $\mathrm{Cu}^{2+}, 0.3 \mathrm{ng} \mathrm{ml}^{-1}$ for rutin, $3 \mathrm{ng} \mathrm{ml}^{-1}$ for sudan II, $10 \mathrm{ng} \mathrm{ml}^{-1}$ for sudan III and $5 \mathrm{ng} \mathrm{ml}^{-1}$ for sudan IV. 


\section{Applications}

\subsection{Determination of sudan I in three contaminated hot chilli products}

The sample of hot chilli sauces, which supplied by Shaanxi Entry-Exit Inspection and Quarantine Bureau, have been confirmed containing sudan dyes. The proposed method was applied to the determination of sudan I in hot chilli sauce. Two samples were prepared in terms of "Sample preparation"; one of the samples was added to $5 \mathrm{ml}$ standard solution $\left(1 \mu \mathrm{g} \mathrm{ml}^{-1}\right)$, respectively. The samples were determined directly and the results were listed in Table 1 .

\subsection{Possible mechanism of the CL reaction}

A possible CL mechanism of luminol-periodate-sudan I was discussed. To support the possible reaction mechanism of sudan I, the absorbance of different solutions was measured by UV/Vis at $220.4 \mathrm{~nm}$, and the results are listed in Table 2. At $220.4 \mathrm{~nm}$, it could be found that both luminol and periodate reacted with sudan I, and the absorbtion intensity of sudan I increased in the presence of periodate and decreased in the presence of luminol. It was also found that the product of reaction between sudan I and periodate could oxidize luminol chemiluminescently.

\section{Conclusions}

A sensitive and simple CL method has been proposed for the determination of sudan I in contaminated hot chilli sauces. Combined with the flow injection system, the enhancive luminol-periodate CL was utilized for determination of sudan I. The present method takes prominent advantages including instrumental simplicity, reduced reagents consumption, improved sensitivity, analytical efficiency, and easy handling procedure as well. The present method offers the promise for routine quality control of pharmaceuticals and determination of sudan I in food analysis.

Table 1

Results of determination of sudan I in Pixian douban, Golden mark guilin chilli sauce and Golden mark satay sauce ${ }^{*}$

\begin{tabular}{|c|c|c|c|c|c|c|}
\hline $\begin{array}{l}\text { Sample } \\
\text { no. }\end{array}$ & $\begin{array}{c}\text { Added } \\
\left(\mathrm{pg} \mathrm{ml}^{-1}\right)\end{array}$ & $\begin{array}{c}\text { Found } \\
\left(\mathrm{pg} \mathrm{ml}^{-1}\right)\end{array}$ & $\begin{array}{l}\mathrm{RSD} \\
(\%)\end{array}$ & $\begin{array}{c}\text { Recovery } \\
(\%)\end{array}$ & $\begin{array}{l}\text { By the proposed method } \\
\qquad\left(\mu \mathrm{g} \mathrm{g}^{-1}\right)\end{array}$ & $\begin{array}{l}\text { By HPLC } \\
\left(\mu \mathrm{g} \mathrm{g}^{-1}\right)\end{array}$ \\
\hline \multirow[t]{2}{*}{1} & 0 & 5.1 & 1.38 & 103.8 & 4.72 & - \\
\hline & 6 & 11.3 & 1.30 & & & \\
\hline \multirow[t]{2}{*}{2} & 0 & 1.6 & 2.76 & 90.5 & & \\
\hline & 4 & 5.2 & 2.44 & & & \\
\hline \multirow[t]{2}{*}{3} & 0 & 1.4 & 2.55 & 91.2 & 1.41 & - \\
\hline & 4 & 5.1 & 1.98 & & & \\
\hline \multirow[t]{2}{*}{4} & 0 & 5.0 & 2.22 & 97.1 & & \\
\hline & 9 & 13.8 & 1.33 & & & \\
\hline \multirow[t]{2}{*}{5} & 0 & 2.5 & 3.09 & 98.7 & 1.35 & 1.33 \\
\hline & 8 & 10.4 & 2.56 & & & \\
\hline \multirow[t]{2}{*}{6} & 0 & 0.6 & 2.84 & 90.0 & & \\
\hline & 2 & 2.4 & 2.01 & & & \\
\hline
\end{tabular}

\footnotetext{
"The average of five determinations. 1, 2: Pixian douban; 3, 4: Golden mark guilin chilli sauce; 5, 6: Golden mark satay sauce.
} 
Table 2

Results of absorbance of different reaction systems by $\mathrm{UV}^{\mathrm{a}}$

\begin{tabular}{lcc}
\hline Types of reaction system & $A_{220.4 \mathrm{~nm}}$ & $I_{\mathrm{CL}}$ \\
\hline Sudan I & 0.3398 & - \\
$\mathrm{KIO}_{4}$ & 0.9575 & - \\
Luminol $+\mathrm{KIO}_{4}$ & 0.6909 & 105 \\
$\mathrm{KIO}_{4}+$ sudan I & 0.7524 & - \\
$\mathrm{KIO}_{4}+$ sudan I + luminol & - & 160 \\
\hline
\end{tabular}

${ }^{\mathrm{a}}$ The concentrations of sudan $\mathrm{I}, \mathrm{KIO}_{4}$ and luminol were $10 \mathrm{pg} \mathrm{ml}^{-1}, 0.5 \mu \mathrm{mol} 1^{-1}$ and $50 \mathrm{nmol} \mathrm{ml}^{-1}$, respectively.

\section{Acknowledgements}

The authors gratefully acknowledge the financial support from Shaanxi Province Nature Science Foundation and Ministry of Education, China, Grant No. 2003B05 and No. 04Jk103.

\section{References}

[1] IARC (International Agency for Research on Cancer), Some Aromatic Azo Compounds, IARC Monograph, Vol. 8, Lyon, 1975, pp. 225-231.

[2] J.J. Childs and D.S. Clayson, The metabolism of 1-phenylazo-2-naphthol in the rabbit, Biochemical Pharmacology 15 (1966), 1247-1258.

[3] K.T. Chung, The significance of azo-reduction in the mutagenesis and carcinogenesis of azo dyes, Mutation Research 114 (1983), 269-281.

[4] M. Stiborová, V. Martinek, H. Martinek, H. Rydlová, P. Hodek and E. Frei, Sudan I is a potential carcinogen for humans: evidence for its metabolic activation and detoxication by human recombinant cytochrome P450 1A1 and liver microsomes, Cancer Research 62 (2002), 5678-5684.

[5] F. Calbiani, M. Careri, L. Elviri, A. Mangia, L. Pistarà and I. Zagnoni, Development and in-house validation of a liquid chromatography-electrospray-tandem mass spectrometry method for the simultaneous determination of sudan I, sudan II, sudan III and sudan IV in hot chilli products, Journal of Chromatography A 1024 (2004), 123-130.

[6] F. Calbiani, M. Careri, L. Elviri, A. Mangia and I. Zagnoni, Accurate mass measurements for the confirmation of sudan azo-dyes in hot chilli products by capillary liquid chromatography-electrospray tandem quadrupole orthogonalacceleration time of flight mass spectrometry, Journal of Chromatography A 1058 (2004), 127-135.

[7] M. Ma, X. Luo, B. Chen, S. Su and S. Yao, Simultaneous determination of water-soluble and fat-soluble synthetic colorants in foodstuff by high-performance liquid chromatography-diode array detection-electrospray mass spectrometry, Journal of Chromatography A 1103 (2006), 170-176.

[8] Y.P. Zhang, Y.J. Zhang, W.J. Gong, A.I. Gopalan and K.P. Lee, Rapid separation of sudan dyes by reverse-phase high performance liquid chromatography through statistically designed experiments, Journal of Chromatography A 1098 (2005), $183-187$.

[9] M. Mazzetti, R. Fascioli, I. Mazzoncini, G. Spinelli, I. Morelli and A. Bertoli, Determination of 1-phenylazo-2-naphthol (Sudan I) in chilli powder and in chilli-containing food products by GPC clean-up and HPLC with LC/MS confirmation, Food Additives and Contaminants 21 (2004), 935-941.

[10] H.G. Daood and P.A. Biacs, Simultaneous determination of Sudan dyes and carotenoids in red pepper and tomato products by HPLC, Journal of Chromatographic Science 43 (2005), 461-465.

[11] V. Cornet, Y. Govaert, G. Moens, J. Van Loco and J. M. Degroodt, Development of a fast analytical method for the determination of sudan dyes in chili- and curry-containing foodstuffs by high performance high performance liquid chromatography-photodiode array detection, Journal Agriculture and Food Chemistry 54 (2006), 639-644.

[12] F. Puoci, C. Garreffa, F. Iemma, R. Muzzalupo, U.G. Spizzirri and N. Picci, Molecularly imprinted solid phase extraction for detection of sudan I in food matrices, Food Chemistry 93 (2005), 349-353.

[13] L. Di Donna, L. Maiuolo, F. Mazzotti, D. De Luca and G. Sindona, Assay of Sudan I contamination of foodstuff by atmospheric pressure chemical ionization tandem mass spectrometry and isotope dilution, Analytical Chemistry 76 (2004), 5104-5108.

[14] F. Capitàn, L.F. Capitàn-Vallvey, M.D. Fernàdez, I. De Orbe and R. Avidad, Determination of colorant matters mixtures in foods by solid-phase spectrophotometry, Analytica Chimica Acta 331 (1996), 141-148. 
[15] F. Tateo and M. Bononi, Fast determination of sudan I by HPLC/APCI-MS in hot chilli, spices, and oven-baked foods, Journal of Agriculture and Food Chemistry 52 (2004), 655-658.

[16] H.O. Albrecht, Uber die Chemiluminescenz des Aminophthalsaurehydrazids, Z. Phys. Chem. 136 (1928), 321-330.

[17] L.P. Palilis and A.C. Calokerinos, Analytical applications of chemiluminogenic reaction. Analytica Chimica Acta 413 (2000), 175-186.

[18] A.M. Powe, K.A. Fletcher, N.N. St. Luce, M. Loury and S. Neal, Molecular fluorescence, phosphorescence, and chemilminescence spectrometry, Analytical Chemistry 76 (2004), 4614-4634.

[19] Y.H. Liu, Z.H. Song, F.X. Dong and L. Zhang, Flow injection chemiluminescence determination of sudan I in hot chili sauce, Journal of Agricultural and Food Chemistry 55 (2007), 614-617. 


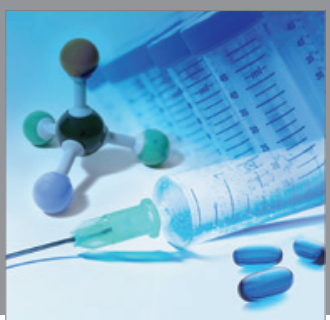

International Journal of

Medicinal Chemistry

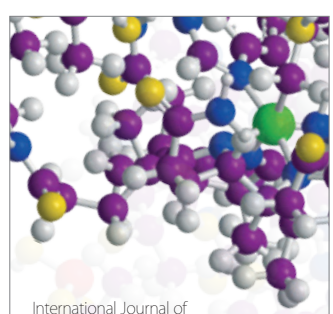

Carbohydrate Chemistry

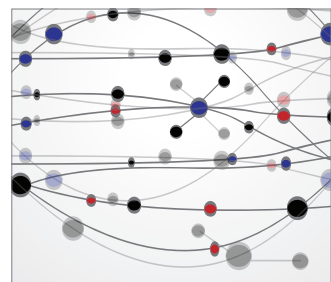

The Scientific World Journal
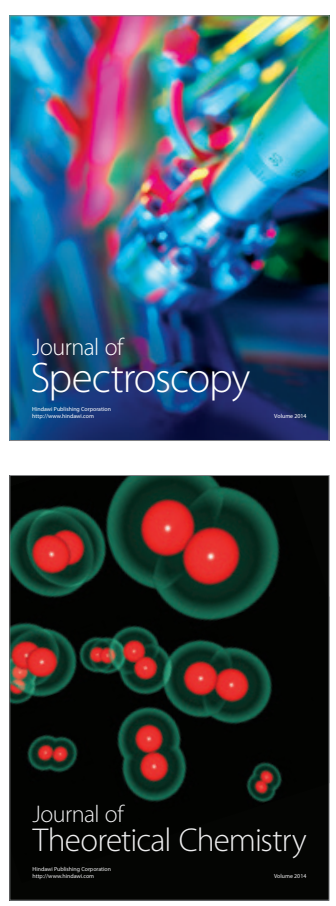
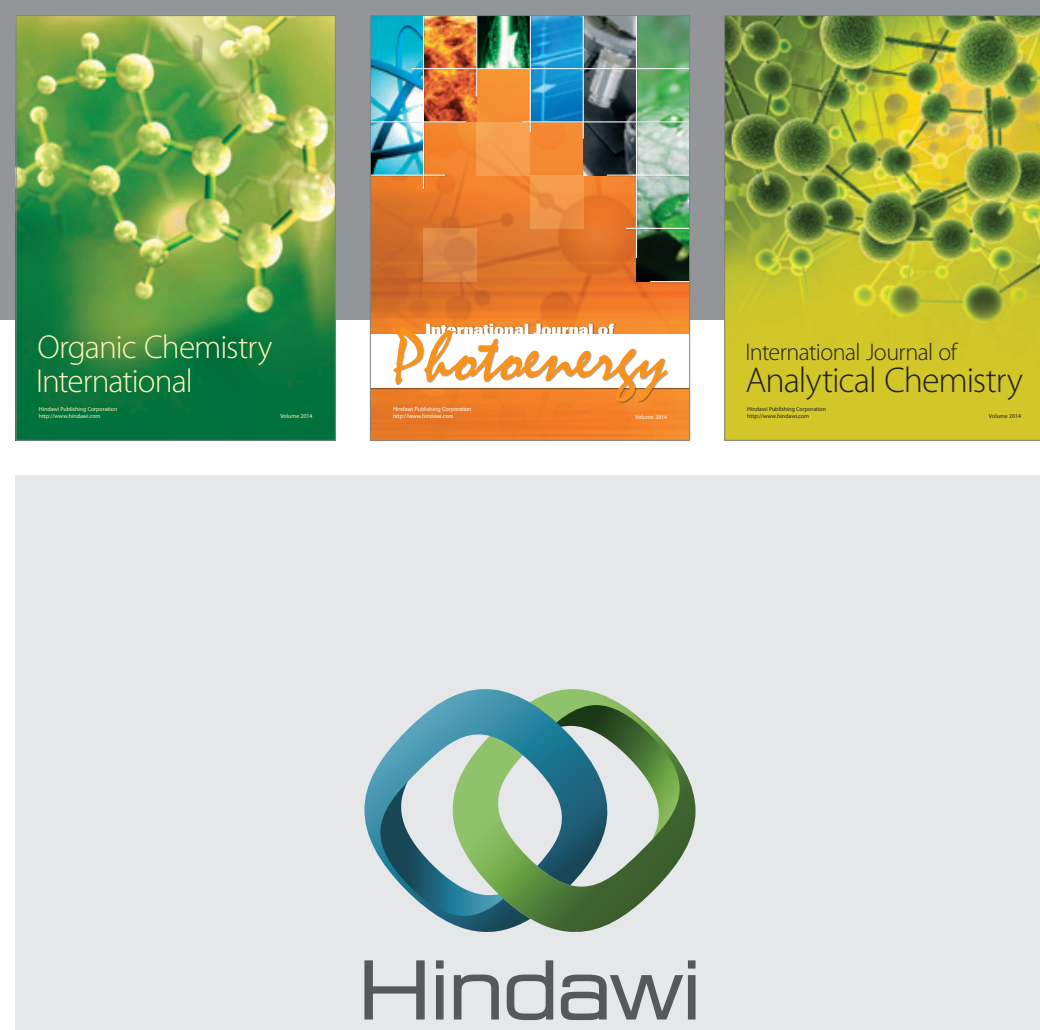

Submit your manuscripts at

http://www.hindawi.com
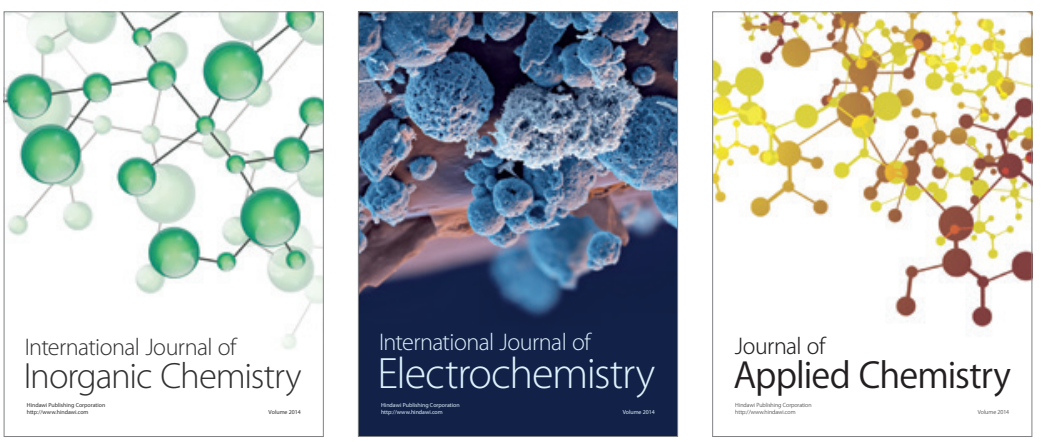

Journal of

Applied Chemistry
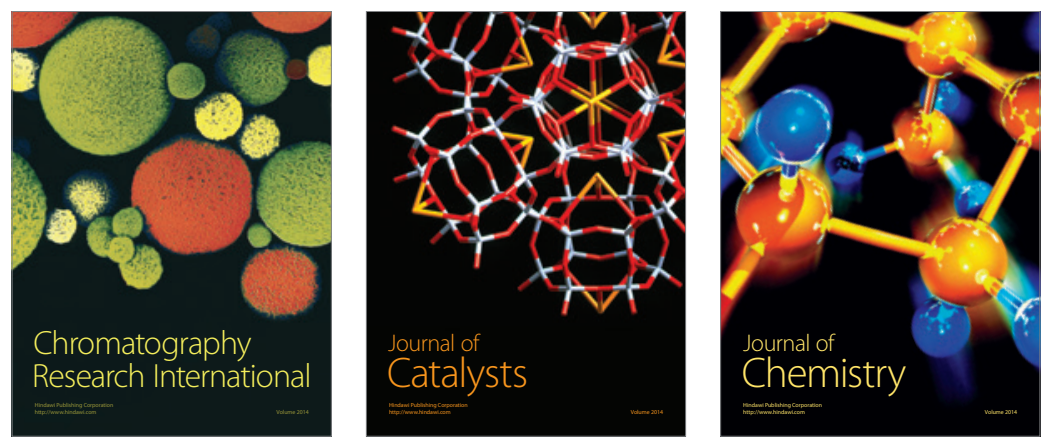
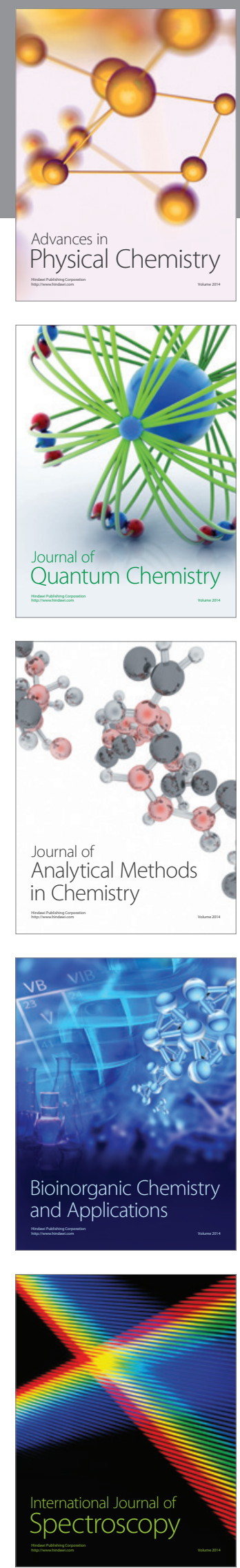